\title{
PENERAPAN METODE ASSOCIATION RULE MENGGUNAKAN ALGORITMA APRIORI PADA SIMULASI PREDIKSI HUJAN WILAYAH KOTA BANDUNG
}

\author{
Mohamad Fauzy ${ }^{1}$, Kemas Rahmat Saleh $\mathbf{W}^{2}$, Ibnu Asror ${ }^{3}$ \\ ${ }^{123}$ Fakultas Informatika Telkom University \\ Jl. Telekomunikasi No.1 Terusan Buah Batu Bandung \\ 1'mrojio12@gmail.com, ${ }^{2}$ bagindokemas@telkomuniversity.ac.id, ${ }^{3}$ iasror@ elkomuniversity.ac.id
}

\begin{abstract}
Abstrak
Prakiraan cuaca saat ini telah menjadi satu hal yang dibutuhkan bagi banyak orang di dunia. Dalam memprediksi hujan pengolahan data cuaca merupakan hal yang penting. Namun permasalahannya, data cuaca yang semakin hari semakin bertambah menyebabkan penumpukan data sehingga pengolahan data tersebut perlu penanganan lebih lanjut. Oleh karena itu pemanfaatan data mining digunakan untuk menyelesaikan masalah ini. Association rule mining adalah salah satu metode data mining yang dapat mengidentifikasi hubungan kesamaan antar item. Penelitian ini dilakukan dengan tiga tahapan utama yaitu : 1) melakukan analisa pola frekuensi tinggi menggunakan algortima apriori; 2) pembentukan aturan asosiasi (association rule); 3) uji kekuatan rule yang terbentuk dengan menghitung lift ratio pada masing-masing rule. Dataset yang digunakan adalah data klimatologi yang diambil dari BMKG stasiun geofisika kelas 1 Bandung. Hasil akhir dari Penelitian ini berupa aturan-aturan asosiasi (association rules) dimana aturan-aturan ini dapat dijadikan sebagai acuan dalam memprediksi cuaca hujan atau tidak hujan untuk satu hari kedepan.
\end{abstract}

Kata kunci :

Data mining, association rule, apriori, prediksi hujan

\section{Abstract}

Weather forecast today has become a necessary thing for many people in the world. In predicting rain weather data processing is essential. But the problem, weather data that is increasingly growing cause the accumulation of data so that the data processing needs further treatment. Therefore, the use of data mining is used to solve this problem. Association rule mining is one of data mining methods that can identify similarity relationships between items. This research is performed by three main stages, namely: 1) to analyze high frequency patterns using algorithms priori; 2) the establishment of an association rule (association rule); 3) test the strength of the rule which is formed by calculating the ratio elevator on each rule. The dataset used is the climatological data taken from BMKG station 1st class geophysical Bandung. The end result of this research in the form of rules of association (association rules) in which these rules can be used as a reference in predicting the weather is rain or not rain for the next day.

Keywords :

data mining, association rule, apriori, rain forecast

\section{Pendahuluan}

Prakiraan cuaca saat ini telah menjadi satu hal yang dibutuhkan bagi banyak orang di dunia. Dalam memprediksi hujan pengolahan data cuaca merupakan hal yang penting. Namun permasalahannya, data cuaca bertambah setiap hari dan prakiraan cuaca dibutuhkan untuk keesokan harinya. Oleh karena itu dibutuhkan teknik data mining yang cepat namun akurat untuk menyelesaikan masalah ini. Salah satu teknik yang dapat diterapkan yaitu Association rule mining(Mujiasih, 2011; Nandagopal, 2010; Santosa, 2007).

Association rule mining adalah salah satu metode data mining yang dapat mengidentifikasi 
hubungan kesamaan antar item("Data Mining Student Notes, QUB,” n.d.; Han, Kamber, \& Pei, 2012). Dalam metode ini dibutuhkan algoritma untuk mencari kandidat aturan asosiasi. Salah satu algoritma yang biasa dipakai adalah algoritma apriori. Kelebihan asosiasi rule dengan apriori ini adalah lebih sederhana dan dapat menangani data yang besar. Sedangkan Algoritma lainnya memiliki kelemahan dalam penggunaan memori saat jumlah data besar, tentunya berpengaruh terhadap banyaknya item yang diproses. Penting tidaknya aturan asosisasi dapat diketahui dengan 2 parameter, minimum support (prosentase kombinasi item dalam database) dan minimum confidence (kuatnya hubungan antar item dalam aturan asosiatif), keduanya ditentukan oleh user(Han et al., 2012). Penggunaan apriori ditujukan untuk menemukan asosiasi rule dalam simulasi prediksi hujan ini yaitu menambang keterhubungan antara item-item yang terkandung dalam data cuaca.

Pada penelitian sebelumnya dilakukan analisis simulasi klasifikasi hujan wilayah kota bandung dengan metoda c4.5, didapatkan hasil akurasi 74.24\%(Effendy, 2014).

Pada penelitian ini, akan melakukan penelitian dengan membuat sistem yang menerapkan metode association rule mining sebagai alat bantu prakiraan cuaca. Data klimatologi dalam satu hari dianggap sebagai satu transaksi. Unsur-unsur yang terdapat di dalam data yaitu suhu, rata kelembapan, rata kecepatan angin, arah angin dan curah hujan masingmasing dianggap sebuah item. Pendekatan yang dilakukan adalah mencari kesamaan-kesamaan antar item pada tiap transaksi. Kemudian dibentuk aturan asosiatif berdasarkan kesamaan-kesamaan tersebut. Aturan asosiatif dijadikan sebagai acuan dalam prakriaan cuaca pada penelitian ini.

Penelitian ini dilakukan dengan tiga tahapan utama yaitu: 1) melakukan analisa pola frekuensi tinggi menggunakan algortima apriori; 2) pembentukan aturan asosiasi (association rule); 3) uji kekuatan rule yang terbentuk dengan menghitung lift ratio pada masing-masing rule. Dataset yang digunakan adalah data klimatologi yang diambil dari BMKG stasiun geofisika kelas 1 Bandung. Hasil akhir dari Penelitian ini berupa aturan-aturan asosiasi (association rules) dimana aturan-aturan ini dapat dijadikan sebagai acuan dalam memprediksi cuaca hujan atau tidak hujan untuk satu hari kedepan

\section{LANDASAN TEORI}

\section{II.1 Association Rule Mining}

Analisis asosiasi atau association rule mining adalah teknik data mining untuk menemukan aturan asosiatif antara suatu kombinasi item. Analisis asosiasi dikenal juga sebagai salah satu teknik data mining yang menjadi dasar dari salah satu teknik data mining lainnya. Secara khusus, salah satu tahap analisis asosiasi yang menarik perhatian banyak peneliti untuk menghasilkan algoritma yang efisien, yaitu analisis pola frekuensi tinggi (frequent pattern mining) (Chengqi, 2002; Han et al., 2012; Han, Pei, Yin, \& Mao, 2004; Kusrini, Luthfi, 2009).

Secara umum association rule mempunyai bentuk : LHS $=>$ RHS dimana LHS dan RHS tersebut adalah himpunan item; jika setiap item-item dalam LHS terdapat dalam transaksi maka item-item dalam RHS juga terdapat dalam transaksi.

Aturan asosiasi biasanya dinyatakan dalam bentuk(Kusrini, Luthfi, 2009):

$\{\mathrm{A}, \mathrm{B}\} \Rightarrow>\mathrm{C}\}($ support $=10 \%$, confidence $=50 \%)$

\section{II.2 Support}

Support dari suatu association rule adalah presentasi kombinasi item tersebut dalam database, dimana jika mempunyai item A dan item B maka support adalah proporsi dari transaksi dalam database yang mengandung A dan B. Rumus untuk menghitung nilai support dari dua item tersebut adalah sebagai berikut(Kusrini, Luthfi, 2009; Kusumo, Bijaksana, \& Darmantoro, 2016):

$$
\begin{aligned}
& \text { Support }(A, B)=P(A \cap B) \\
& \text { Support }(A, B)=\frac{\sum \text { Transahsi mengandung } A \text { dan } B}{\sum \text { Transahsi }}
\end{aligned}
$$

\section{II.3 Confidence}

Confidence dari association rule adalah ukuran ketepatan suatu rule, yaitu presentasi transaksi dalam 
database yang mengandung A dan mengandung B. Dengan adanya confidence kita dapat mengukur kuatnya hubungan antar-item dalam association rule. Rumus untuk menghitung nilai confidence dari dua item tersebut adalalah sebagai berikut(Kusrini, Luthfi, 2009; Kusumo et al., 2016):

$$
\begin{aligned}
& \text { Confidence }=P(B \mid A) \\
& \text { Confidence }=\frac{\sum \text { Transaksi mengandung } A \text { dan } B}{\sum \text { Transaksi mengandung } A}
\end{aligned}
$$

\section{II.4 Apriori}

Algoritma apriori adalah langkah untuk proses menemukan frequent-itemset dengan melakukan iterasi pada data. Dimana itemset adalah himpunan item-item yang berada di dalam himpunan yang diolah oleh sistem, sedangkan frequent-itemset menunjukan itemset yang memiliki frekuensi kemunculan lebih dari nilai minimum yang telah ditentukan (ф). Pada iterasi ke- $k$, semua itemset yang ditemukan yang memiliki $k$ item disebut $k$-itemset. Setiap iterasi terdiri dari dua tahap yaitu pembangkitan kandidtat dan pembangkitan rule.

Pada tahap pembangkitan kandidat (candidat generation) dimana himpunan semua frequent $(k-1)$ -

itemset $F_{k-1}$ yang digunakan pada pass ke- $(k-1)$ digunakan untuk membangkitkan kandidat itemset

$C_{\mathbb{k}}$. Prosedur pembangkitan kandidat menjamin bahwa $C_{k}$ adalah superset dari himpunan. Kemudian di-scan dalam tahap perhitungan support (support

counting). Pada akhir pass $C_{k}$ diperiksa untuk menentukan kandidat mana yang muncul, menghasilkan $F_{k}$. Perhitungan support berakhir ketika $C_{k}$ atau $C_{k+1}$ kosong.

Pada tahap membangkitkan rule, akan dibangkitkan lebih dahulu candidate rule. Candidate rule berisi semua kemungkinan rule yang memiliki support $>$ minimum support karena inputan candidate rule adalah frequent-itemset. Kemudian candidate rule akan di-join dengan table $\mathrm{F}$ untuk menemukan support antecedent. Confidence rule dihitung dengan cara membandingkan support rule dengan support antecendent rule. Hanya rule yang mempunyai confidence > minimum confidence yang disimpan dalam table rule (table R)(Kusumo et al., 2016).

\section{II.5 Lift Ratio}

Lift ratio adalah suatu ukuran untuk mengetahui kekuatan aturan asosisasi (association rule) yang telah terbentuk. Nilai lift ratio biasanya digunakan sebagai penentu apakah aturan asosiasi valid atau tidak valid. Untuk menghitung lift ratio digunakam rumus sebagai berikut:

$$
\text { Lift Ratio }=\frac{\text { Confidence }(A, B)}{\text { Benchmark Confidence }(A, B)}
$$

Untuk mendapatkan nilai benchmark confidence sendiri dapat dihitung menggunakan rumus sebagai berikut:

$$
\text { Benchmark Confidence }=\frac{N e}{N}
$$

Keterangan:

- $\mathrm{Nc}=$ jumlah transaksi dengan item yang menjadi consequent

- $\quad \mathrm{N}=$ jumlah transaksi basis data.

\section{ANALISIS DAN PERANCANGAN}

\section{III.1 Kebutuhan Sistem}

Skenario keseluruhan sistem :

1. Data training dan data testing adalah data yang sudah melalui proses preprocessing secara manual.

2. Dengan menggunakan algoritma apriori akan dilakukan training terhadap itemset yang terdapat di dalam data klimatologi yaitu dengan membentuk kandidat kandidat itemset atau biasa disebut dengan $\mathrm{k}$-itemset.

3. Setiap k-itemset yang terbentuk sebelumnya kemudian dilakukan perhitungan nilai support untuk menghitung jumlah transaksi yang memuat semua item di dalam k-itemset tersebut. $\mathrm{K}$-itemset yang nilai supportnya lebih tinggi dari nilai minimum support kemudian dijadikan kandidat sebagai pembentukan aturan asosiasi (association rule).

4. Dilakukan perhitungan confidence dari tiap kitemset untuk menentukan apakah kandidat tersebut dapat dijadikan sebagai aturan asosiasi (association rule) atau tidak. 
Rule yang terbentuk di evaluasi kekuatannya dengan cara uji lift ratio. Nilai lift ratio dari sebuah rule didapatkan melalui perbandingan confidence rule tersebut dengan benchmark confidence

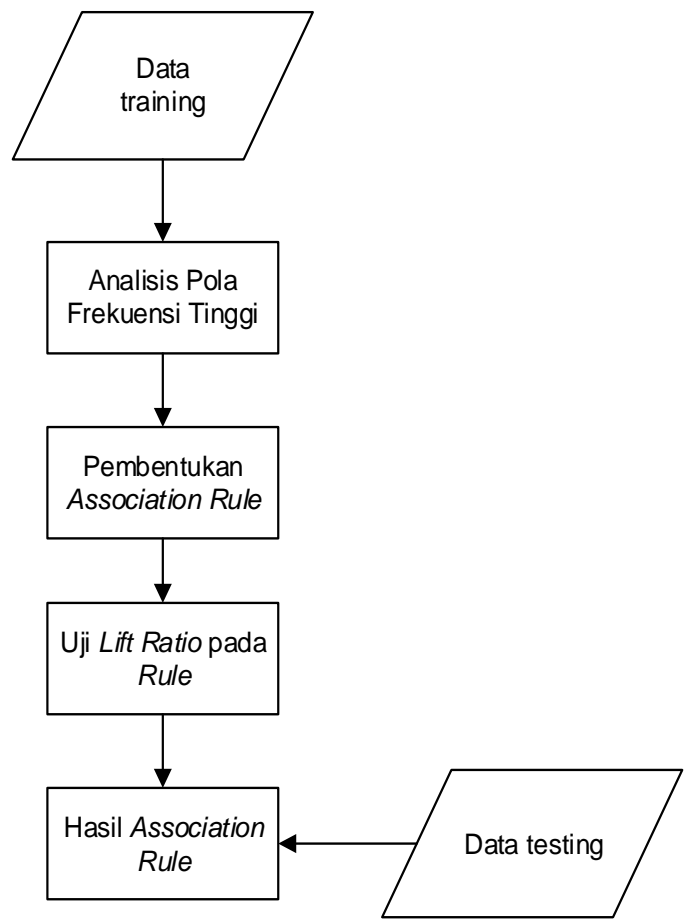

Gambar 1. Perancangan Umum Sistem

Selanjutnya dikeluarkan hasil akhir aturan asosiasi dengan format jika (k-itemset) maka hujan atau tidak hujan. Nilai k-itemset tergantung berdasarkan k-itemset yang terbentuk.

\section{III.2 Dataset}

Dataset yang digunakan oleh sistem yang dibangun berupa file bertipe excel yang berisikan data cuaca yang diambil dari BMKG stasiun geofisika kelas 1 Bandung. Penginputan data ke file excel dilakukan secara manual karena data yang di dapat dari BMKG merupakan data fisik. Lalu data akan masuk ke proses data preprocessing yang akan menghasilkan dataset yang akan dipakai oleh sistem

\section{III.3 Tujuan Pengujian}

Tujuan dari pengujian yang dilakukan adalah sebagai berikut ini:
1. Menganalisa pengaruh minimum support terhadap jumlah frequent itemset yang dibangkitkan algoritma aproiri.

2. Menganalisa pengaruh minimum confidence terhadap jumlah rule yang dihasilkan berdasarkan frequent itemset.

3. Menganalisa pengaruh minimum support dan minimum confidence terhadap akurasi dari sistem yang telah dibangun.

4. Mengetahui kekuatan dari tiap rule yang dihasilkan.

\section{III.4 Analisis Hasil Pengaruh Minimum Support dan Minimum Confidence terhadap Frequent Itemset.}

Tabel 1. Frequent itemset

\begin{tabular}{llllll}
\hline \hline mincoflminsup & $\mathbf{1 0 \%}$ & $\mathbf{2 0 \%}$ & $\mathbf{3 0 \%}$ & $\mathbf{4 0 \%}$ & $\mathbf{5 0 \%}$ \\
\hline \hline $50 \%$ & 73 & 40 & 19 & 17 & 7 \\
$60 \%$ & 73 & 40 & 19 & 17 & 7 \\
$70 \%$ & 73 & 40 & 19 & 17 & 7 \\
\hline \hline
\end{tabular}

Berdasarkan tabel 1, dapat dilihat jumlah frequent itemset terbanyak dibangkitkan oleh minimum support terkecil dalam pengujian ini yaitu $10 \%$, sedangkan frequent itemset paling sedikit dibangkitkan oleh minimum support sebesar 50\%. Hal ini dikarenakan nilai minimum support adalah nilai acuan dalam perhitungan sebuah itemset. Hanya itemset yang nilai supportnya sama atau lebih besar dari nilai minimum support saja yang dijadikan sebagai frequent itemset. Sedangkan minimum confidence tidak memiliki pengaruh dalam pembangkitan frequent itemset karena tidak terjadi perhitungan confidence pada tahap ini. Maka dapat disimpulkan bahwa semakin tinggi minimum support yang digunakan maka akan semakin sedikit jumlah frequent itemset yang dibangkitkan

\section{III.5 Analisis Hasil Pengaruh Minimum Support Minimum dan Confidence terhadap Rule.}

Berdasarkan tabel 2, dapat dilihat jumlah aturan aosiatif yang terbentuk terbanyak dihasilkan oleh 
minimum support $10 \%$ dan minimum confidence $50 \%$ yaitu sebanyak 9 rule.

Tabel 2. Jumlah rule

\begin{tabular}{llllll}
\hline \hline mincoflminsup & $\mathbf{1 0 \%}$ & $\mathbf{2 0 \%}$ & $\mathbf{3 0 \%}$ & $\mathbf{4 0 \%}$ & $\mathbf{5 0 \%}$ \\
\hline \hline $50 \%$ & 9 & 5 & 2 & 2 & 0 \\
$60 \%$ & 3 & 1 & 0 & 0 & 0 \\
$70 \%$ & 2 & 0 & 0 & 0 & 0 \\
\hline \hline
\end{tabular}

Pada setiap pertambahan nilai minimum support dan minimum confidence yang diujikan terlihat rule yang terbentuk semakin berkurang. Penurunan ini dipengaruhi oleh jumlah frequent itemset yang dibangkitkan pada pengujian sebelumnya. Pada minimum support $50 \%$ dapat dilihat tidak terbentuk satu pun aturan asosiatif, hal ini diakibatkan nilai confidence dari frequent itemset yang dibangkitkan tidak ada yang memenuhi syarat minimum confidence yang diujikan. Oleh karena itu, dapat dilihat bahwa minimum confidence berpengaruh pada pembentukan rule. Pada pengujian ini dapat disimpulkan semakin tinggi minimum support dan minimum confidence yang digunakan maka rule yang dihasilkan akan semakin sedikit

\section{III.6 Analisis Hasil Pengaruh Minimum Support Minimum dan Confidence terhadap akurasi.}

Tabel 3. Akurasi data training

\begin{tabular}{llllll}
\hline \hline mincoflminsup & $\mathbf{1 0 \%}$ & $\mathbf{2 0 \%}$ & $\mathbf{3 0 \%}$ & $\mathbf{4 0 \%}$ & $\mathbf{5 0 \%}$ \\
\hline \hline $50 \%$ & 76.8 & 76.7 & 49.7 & 49.7 & 0 \\
$60 \%$ & 42.7 & 26.7 & 0 & 0 & 0 \\
$70 \%$ & 15.9 & 0 & 0 & 0 & 0 \\
\hline \hline
\end{tabular}

Berdasarkan tabel 3 di atas, akurasi tertinggi diperoleh sebesar $76.78 \%$ dengan minimum support $10 \%$ dan minimum confidence $50 \%$. Sedangkan pada minimum support $50 \%$, dan yang bernilai akurasi 0 lainnya tidak dapat dihitung besarnya akurasi karena tidak ada rule yang terbentuk. Dari grafik diatas dapat disimpulkan semakin tinggi minimum support dan minimum confidence yang digunakan maka akurasi yang dihasilkan akan semakin kecil. Hal ini terjadi karena rule-rule yang dihasilkan semakin kuat keterkaitan antar item-nya. Sehingga pada saat data training diuji kedalam rule dan dibandingkan kembali dengan data training nilai kebenarannya semakin berkurang. Nilai tersebut di prosentasekan dan dijadikan nilai akurasi dari data training. Dalam pengujian akurasi data training dapat dilihat sistem berfungsi optimal pada minimum support sebesar $20 \%$ dan minimum confidence sebesar 50\% yang menghasilkan akurasi sebesar $76.71 \%$.

Tabel 4. Akurasi data testing

\begin{tabular}{llllll}
\hline \hline mincoflminsup & $\mathbf{1 0 \%}$ & $\mathbf{2 0 \%}$ & $\mathbf{3 0 \%}$ & $\mathbf{4 0 \%}$ & $\mathbf{5 0 \%}$ \\
\hline \hline $50 \%$ & 75.9 & 75.9 & 50.4 & 50.4 & 0 \\
$60 \%$ & 30.69 & 24.11 & 0 & 0 & 0 \\
$70 \%$ & 6.58 & 0 & 0 & 0 & 0 \\
\hline \hline
\end{tabular}

Berdasarkan tabel 4 di atas, akurasi tertinggi diperoleh sebesar $75.89 \%$ terdapat pada dua minimum support berbeda yaitu minimum support $10 \%$ dan minimum support $20 \%$ dengan minimum confidence 50\%. Akurasi berikutnya juga diperoleh pada dua minimum support yang berbeda yaitu minimum support $30 \%$ dan minimum support $40 \%$ dengan minimum confidence $50 \%$ sebesar $50.41 \%$. Sedangkan pada minimum support $50 \%$, dan yang bernilai akurasi 0 lainnya tidak dapat dihitung besarnya akurasi karena tidak ada rule yang terbentuk. Dari grafik diatas dapat disimpulkan semakin tinggi minimum support dan minimum confidence yang digunakan maka akurasi yang dihasilkan akan semakin kecil. Hal ini terjadi karena rule-rule yang dihasilkan semakin kuat keterkaitan antar item-nya. Sehingga pada saat data testing diuji kedalam rule dan dibandingkan kembali dengan data testing nilai kebenarannya semakin berkurang. Nilai tersebut di prosentasekan dan dijadikan nilai akurasi dari data testing. Dalam pengujian akurasi data testing dapat dilihat sistem berfungsi optimal pada minimum support sebesar $20 \%$ dan minimum confidence sebesar 50\% yang menghasilkan akurasi sebesar $75.89 \%$.

\section{III.7 Analisis Hasil Lift Ratio terhadap Hasil Rule.}

Berdasarkan tabel 5 berikut lift ratio untuk semua rule yang berhasil dibentuk memiliki nilai lebih besar dari 1 (lift ratio >1). Hal ini menunjukan bahwa semua rule tersebut bersifat kuat dan valid untuk digunakan sebagai acuan dalam memprediksi hujan. 


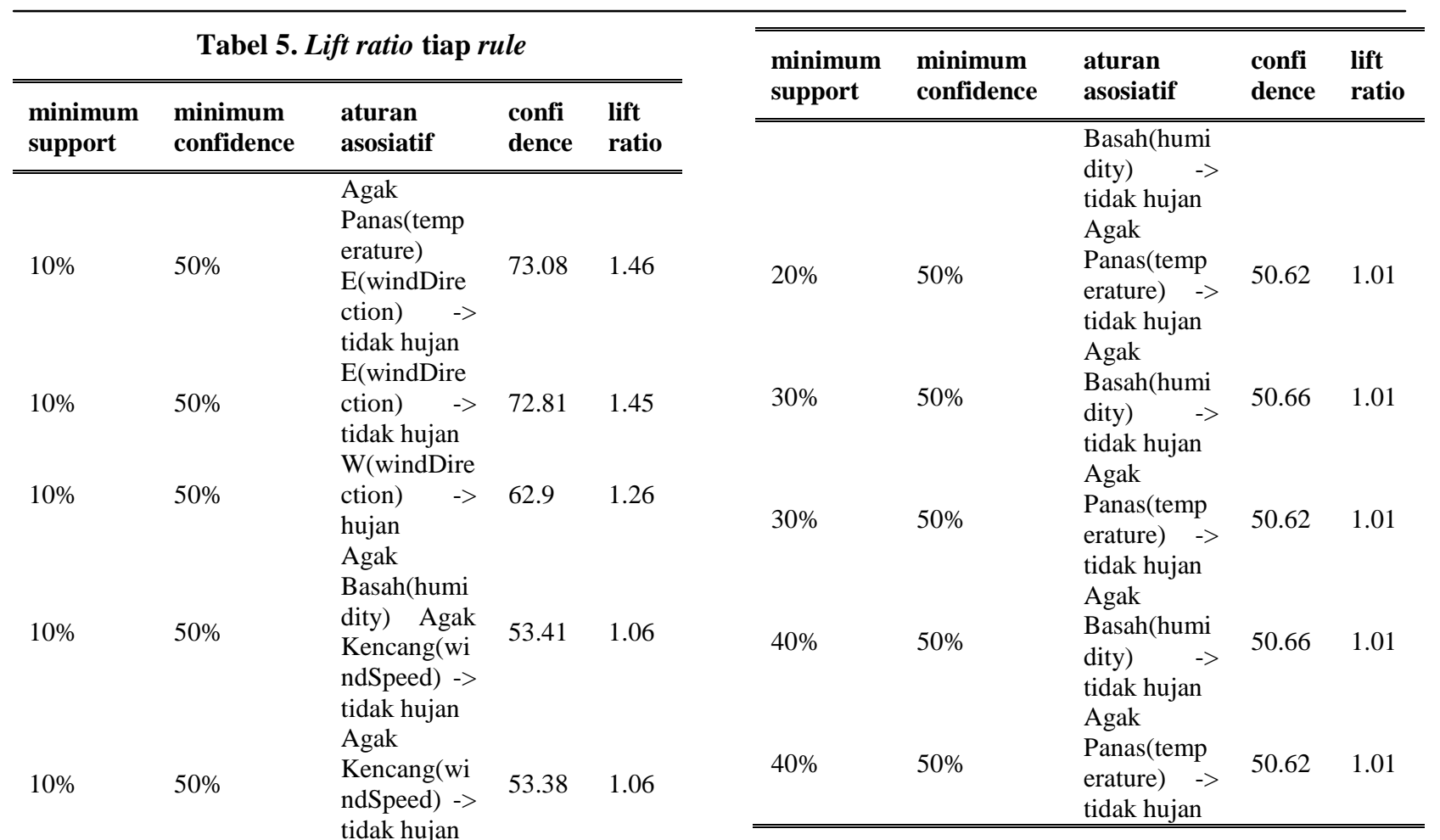

Agak

Panas(temp

$10 \% \quad 50 \% \quad$ erature)

Pelan(wind

$51.94 \quad 1.03$

Speed) ->

tidak hujan

Pelan(wind

$10 \% \quad 50 \%$

Speed) ->

tidak hujan

Agak

$10 \% \quad 50 \%$

Basah(humi

dity)

tidak hujan

Agak

$\begin{array}{lllll}10 \% & 50 \% & \text { Panas(temp } & 50.62 & 1.01\end{array}$

erature) $\rightarrow$

tidak hujan

W(windDire

$20 \% \quad 50 \%$

ction)

$62.9 \quad 1.26$

hujan

Agak

Panas(temp

$20 \% \quad 50 \% \quad$ erature)

Pelan(wind

$51.94 \quad 1.03$

Speed) $\quad \rightarrow$

tidak hujan

Pelan(wind

\begin{tabular}{|c|c|c|c|c|}
\hline $20 \%$ & $50 \%$ & $\begin{array}{l}\text { Speed) } \quad \rightarrow \\
\text { tidak hujan }\end{array}$ & 50.88 & 1.01 \\
\hline $20 \%$ & $50 \%$ & Agak & 50.66 & 1.01 \\
\hline
\end{tabular}

\section{KESIMPULAN DAN SARAN}

Metode association rule mining dengan menggunakan algoritma apriori dapat diterapkan pada sistem simulasi prediksi hujan. Semakin tinggi minimum support dan minimum confidence yang digunakan maka semakin sedikit jumlah frequent itemset dan rule yang terbentuk serta akurasi semakin berkurang. Semua rule yang dihasilkan pada penelitian ini memiliki nilai lift ratio lebih dari 1.00 sehingga dapat digunakan sebagai acuan dalam memprediksi hujan

Untuk saran untuk penelitian adalah kategori yang dilakukan pada penelitian ini adalah hujan dan tidak hujan. Untuk kedepannya dapat dilakukan pengkategorian yang lebih luas sehingga dapat diketahui intensitas hujan yang turun. Untuk selanjutnya dapat menggunakan dataset yang jauh lebih besar dari sekarang, misalnya data yang diolah sebanyak 10 tahun keatas. Diharapkan untuk penelitian selanjutnya dapat menerapkan algoritma pembangkitan frequent itemset yang berbeda, seperti FP-Growth. 


\section{REFERENSI}

Chengqi, Z. (2002). Association Rule Mining: Models and Algorithms.

Data Mining Student Notes, QUB. (n.d.). Retrieved from http://www.pcc.qub.ac.uk/tec/courses/datamini ng/stu_notes/dm_book_1.html

Effendy, T. H. H. V. (2014). Simulasi Klasifikasi Hujan WIlayah Kota Bandung dengan Metode Decision Tree Menggunakan C4.5.

Han, J., Kamber, M., \& Pei, J. (Computer scientist). (2012). Data mining : concepts and techniques. Elsevier/Morgan Kaufmann.

Han, J., Pei, J., Yin, Y., \& Mao, R. (2004). Mining frequent patterns without candidate generation: A frequent-pattern tree approach. Data Mining and Knowledge Discovery, 8(1), 53-87. http://doi.org/10.1023/B:DAMI.0000005258.31 418.83

Kusrini, Luthfi, E. T. (2009). Algoritma Data Mining. Andi Yogyakarta.

Kusumo, D., Bijaksana, M., \& Darmantoro, D. (2016). Data Mining Dengan Algoritma Apriori Pada RDBMS Oracle. Jurnal Penelitian Dan, 1-5. Retrieved from http://www.tektrika.org/index.php/tektrika/artic le/download/10/2

Mujiasih, S. (2011). Pemanfaatan Data Mining Untuk Perkiraan Cuaca.

Nandagopal, S. (2010). Mining of Meteorological Data Using Modified Apriori Algorithm. European Journal of Scientific ..., 47(2), 295$308 . \quad$ Retrieved from http://scholar.google.com/scholar?hl=en\&btnG $=$ Search\&q=intitle:Mining + of + Meteorological +Data+Using+Modified+Apriori+Algorithm\#2

Santosa, B. (2007). Teknik Pemanfaatan Data untuk Keperluan Bisnis. Yogyakarta: Graha Ilmu Bisni. 